\title{
Long-Term Renal Safety Profile of Ibandronate 6 mg Infused over 15 Minutes
}

\author{
Roger von Moos ${ }^{\mathrm{a}} \quad$ Clemens B. Caspar ${ }^{\mathrm{b}}$ \\ Kerstin Schmieding ${ }^{f}$ Beat Thürlimann ${ }^{e}$ \\ a'Medizinische Klinik (Onkologie und Hämatologie), Chur, \\ ${ }^{b}$ Medizinische Onkologie, Kantonsspital Baden, \\ 'Frauenspital Fontana, Chur, \\ 'Stadtspital Waid, Zürich, \\ eKantonsspital St Gallen, St Gallen, \\ ${ }^{f}$ Roche Pharma (Schweiz) AG, Reinach, Switzerland
}

Rolf Steiner $^{c}$ Rahel Angst $^{d} \quad$ Roman Inauen $^{\mathrm{e}}$

\section{Key Words}

Breast cancer - Ibandronate · Renal safety .

Bone metastasis

\section{Summary}

Background: In an earlier study, intravenous (i.v.) ibandronate $6 \mathrm{mg}$ administered every 3-4 weeks had a similarly good renal safety profile whether infused over 15 or $60 \mathrm{~min}$ in women with breast cancer and bone metastases. This current study focuses on the renal safety of the extended use of ibandronate. Patients and Methods: Patients completing the original study could choose to enter a follow-up phase and continue (or switch) to receive ibandronate $6 \mathrm{mg}$ by 15-min i.v. infusion every 3-4 weeks. The primary endpoint was the percentage of patients with a serum creatinine increase of $\geq 44.2 \mu \mathrm{mol} / \mathrm{l}(=0.5 \mathrm{mg} / \mathrm{dl}$ ) from core baseline. Results: Fourteen patients entered the follow-up phase and received a median of 16 infusions (range: 9-24). No patient reached the primary endpoint. Most adverse events were mild to moderate in intensity. None of the 6 reported treatment-related adverse events was considered severe or reported as a serious adverse event. Conclusions: Ibandronate was well tolerated when administered as a 6 -mg i.v. infusion over 15 min every 3-4 weeks during the follow-up phase to the earlier core study. No evidence of any treatment-related deterioration in renal function was noted, and no new or unexpected adverse events occurred.

\author{
Schlüsselwörter \\ Brustkrebs · Ibandronat · Nierensicherheit · Knochen- \\ metastasen
}

\section{Zusammenfassung}

Hintergrund: In einer früher publizierten Studie konnte gezeigt werden, dass lbandronat $6 \mathrm{mg}$ intravenös (i.v.) alle 3-4 Wochen infundiert über 15 oder $60 \mathrm{~min}$ bei Brustkrebspatientinnen mit Knochenmetastasen ein gleich gutes renales Sicherheitsprofil hat. In der aktuellen Studie werden renale Sicherheitsdaten von Ibandronat im Langzeitgebrauch gezeigt. Patienten und Methoden: Patientinnen, welche die initiale Studie abgeschlossen hatten, konnten in diese Follow-up-Studie aufgenommen werden. Alle Patientinnen erhielten unabhängig von der früheren Infusionszeit lbandronat i.v. über 15 Minuten alle 3-4 Wochen. Der primäre Endpunkt war der prozentuale Anteil von Patientinnen mit einem Serum-Kreatinin-Anstieg von $\geq 44,2 \mu \mathrm{mol} / /$ ( $=0,5 \mathrm{mg} / \mathrm{dl}$ ) vom Initialwert. Ergebnisse: Vierzehn Patientinnen wurden in diese Anschluss-Studie rekrutiert und erhielten median 16 Infusionen (Spanne: 9-24). Keine Patientin erreichte den primären Endpunkt. Die meisten Nebenwirkungen waren mild bis moderat. Keine der behandlungsassoziierten Nebenwirkungen wurde als schwer oder als schwerwiegender Zwischenfall beurteilt. Schlussfolgerungen: Ibandronat als 6-mg-Infusion über 15 min alle 3-4 Wochen war während dieser Anschluss-Studie gut verträglich. Es konnte keine Verschlechterung der Nierenfunktion festgestellt werden. Ebenso tauchten keine neuen oder unerwarteten Nebenwirkungen auf.

\begin{tabular}{ll}
\hline KARGER & $\oplus$ 2010 S. Karger GmbH, Freiburg \\
Fax +497614520714 & Accessible online at: \\
Information@Karger.de & www.karger.com/onk \\
www.karger.com &
\end{tabular}




\section{Introduction}

Bisphosphonates are standard treatment to prevent skeletal complications of bone metastases $[1,2]$. In patients with metastatic breast cancer, the American Society of Clinical Oncology guidelines recommend starting bisphosphonates at the time of diagnosis of radiologically confirmed bone metastases, and to continue this treatment until there is a substantial decline in performance status [3]. Ibandronate, a nitrogencontaining bisphosphonate, is indicated for the prevention of skeletal-related events in patients with breast cancer and bone metastases [4]. Studies of ibandronate $6 \mathrm{mg}$ intravenous (i.v.) have demonstrated significantly reduced skeletal morbidity period rates (number of 12-week periods with new bone events) compared with placebo $(\mathrm{p}=0.004)$, decreases in bone pain scores and analgesic use, and an improved quality of life [5-7]. Some nitrogen-containing bisphosphonates are associated with an increased risk of renal toxicity, especially after rapid i.v. infusion [8-13]. In two double-blind, randomized phase III studies comparing zoledronic acid with denosumab, renal failure was reported in $2.5 \%$ of patients with breast cancer [14] and in $2.8 \%$ of patients with advanced cancer (excluding breast and prostate cancer) or multiple myeloma [15] receiving zoledronic acid. A study of the effect on renal function of repeated 15-min infusions of ibandronate $6 \mathrm{mg}$ in women with breast cancer and bone metastases was completed in 10 centers in Austria, 7 centers in Switzerland, and 1 center in Germany [16]. Patients received ibandronate $6 \mathrm{mg}$ i.v. either as a $15-\mathrm{min}$ infusion $(n=102)$ or a 60 -min infusion $(n=28)$ every 3 or 4 weeks for 6 months. The 60 -min arm was regarded as the control arm. The results showed that ibandronate administered over 15 min was well tolerated with a safety profile consistent with that of the 60-min infusion. No evidence for any treatment-related deterioration in renal function was seen, as assessed by the change from baseline in serum creatinine, calculated creatinine clearance, or in the urinary excretion of markers of glomerular and tubular function. After the completion of the 6-month core trial, patients enrolled in the Swiss centers were given the option to enter a follow-up phase until reimbursement. Patients could choose either to continue treatment with the 15 -min infusion of i.v. ibandronate every 3 or 4 weeks or to switch to oral ibandronate (50 $\mathrm{mg}$ tablets daily). The objective of the follow-up phase was to continue to investigate the safety and tolerability of 15-min i.v. ibandronate infusions, with special focus on nephrotoxicity. Patients opting for oral ibandronate were not followed after the final visit of the core trial. To date, this is the first published long-term prospective study of ibandronate with a primary endpoint of renal safety.

\section{Patients and Methods}

Study Design

A prospective, multicenter, open-label study was conducted for a total of 18 months between September 2004 and February 2006 at 2 centers in Switzerland.
Inclusion and Exclusion Criteria

Eligible women were aged $\geq 18$ years with histologically or cytologically confirmed breast cancer and at least one osteolytic, mixed or blastic bone metastasis confirmed by X-ray, computed tomography, or magnetic resonance imaging, and had completed the 6-month treatment phase of the core trial. Exclusion criteria for the core study were as reported previously [16]. The study was conducted in accordance with the Declaration of Helsinki (1996) with ethical approval from local ethics committees and patients' written informed consent.

\section{Treatment}

Ibandronate $6 \mathrm{mg}$ i.v. infusions were administered over 15 min every 3 or 4 weeks. A time window of \pm 7 days and a change of schedule were permitted. In contrast to the core trial, but as occurs in clinical practice, unrestricted use of concomitant treatment was allowed. Medications known to be nephrotoxic could be used with caution.

\section{Assessments}

Blood samples for the assessment of serum creatinine and calculated creatinine clearance (Cockcroft-Gault formula) were taken at each study visit (visits 8-14). Routine urinalysis laboratory tests ( $\alpha$-2-macroglobulin, immunoglobulin G, transferrin, albumin, $\alpha$-1-microglobulin, retinol-binding protein, total protein, creatinine, monoclonal free light chains (BenceJones protein), and dipstick results of erythrocytes, leucocytes, and nitrite) were performed at each scheduled visit, and vital signs (blood pressure, pulse, weight, body mass index, and body temperature) were assessed at visits 12 and 14. Blood and urine tests were performed at a central laboratory, but, unlike in the core phase of the trial, the results were not required before the next infusion. Adverse events (AEs) were monitored throughout the study.

\section{Endpoints}

As in the core study, the primary endpoint was the percentage of patients with a serum creatinine increase of $\geq 44.2 \mu \mathrm{mol} / \mathrm{l}(=0.5 \mathrm{mg} / \mathrm{dl})$ from baseline.

\section{Statistical Analysis}

Continuous data were summarized by mean, standard deviation, median, and range (minimum, maximum). Categorical data were presented using absolute and relative frequencies.

\section{Results}

Two of 7 Swiss centers participated in the follow-up phase. These 2 sites had enrolled 27 patients in the core study (15-min arm: 23 patients; 60-min arm: 4 patients). Of the 22/27 patients who completed the 6-month core trial, 14 were enrolled into the follow-up phase. 13 of the 14 patients continued with the 15-min i.v. infusion to which they had been randomized at study entry, and 1 patient switched from the 60 -min i.v. infusion arm to the ibandronate 15 -min i.v. infusion (fig. 1). 6 patients decided to continue treatment with ibandronate tablets. Two patients continued with 15-min i.v. infusions of ibandronate outside the follow-up phase, because their health insurance provided reimbursement. The median number of infusions was 16 (range: 9-24); 8 patients $(56 \%)$ received $\geq 16$ infusions ( 2 patients $(14 \%)$ received 23 infusions and a further 2 patients (14\%) received 24 infusions). 


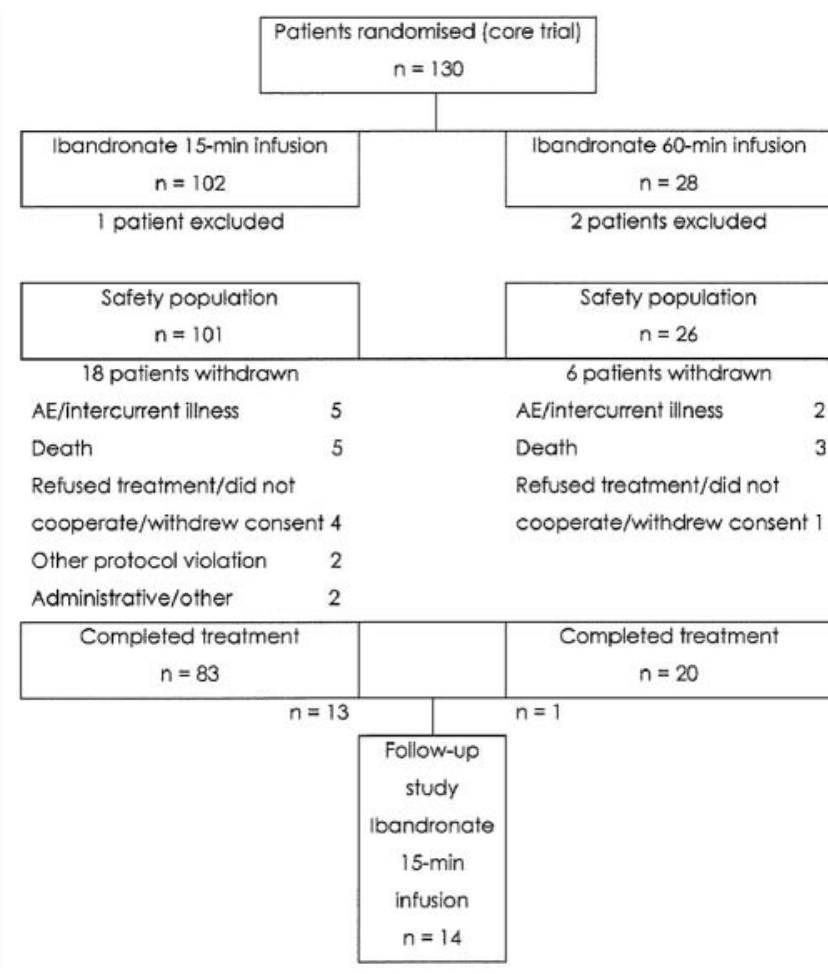

Fig. 1. Patient disposition for core trial (6 months duration) and followup study (12 months).

\section{Renal Function}

None of the 14 patients included in the follow-up phase met the criteria for an increase from baseline in serum creatinine of $\geq 44.2 \mu \mathrm{mol} / 1$. No obvious relationship between the number of ibandronate infusions and either serum creatinine levels or the change from baseline in serum creatinine was observed; both remained relatively stable throughout the core study and follow-up period (fig. 2). For patients enrolled in the follow-up phase, the mean baseline serum creatinine value was $59.4 \pm 10.6 \mu \mathrm{mol} / \mathrm{l}$, and the mean baseline calculated creatinine clearance was $93.5 \pm 28.5 \mathrm{ml} / \mathrm{min}$ (fig. 3). No clinically relevant change from baseline in either parameter was observed over the course of the trial: changes of between 1.3 and $-10.6 \mu \mathrm{mol} / \mathrm{l}$ for mean serum creatinine values and between 17.3 and $-1.8 \mathrm{ml} / \mathrm{min}$ for calculated creatinine clearance were observed (fig. 3). No clinically relevant urinalysis findings were noted during the follow-up phase.

\section{Adverse Events}

All 14 patients reported at least $1 \mathrm{AE}$ during the follow-up phase. Arthralgia and nausea were reported by 5 patients $(36 \%)$ and were the most commonly reported AEs. Fatigue was reported by 4 patients (29\%), and bone pain, paresthesia, nasopharyngitis, and cough by 3 patients $(21 \%)$ each. Two patients (14\%) reported musculoskeletal chest pain, extremity pain, anorexia, vomiting, and toothache. The majority of AEs were mild or moderate (grade 1/2) in intensity. Four

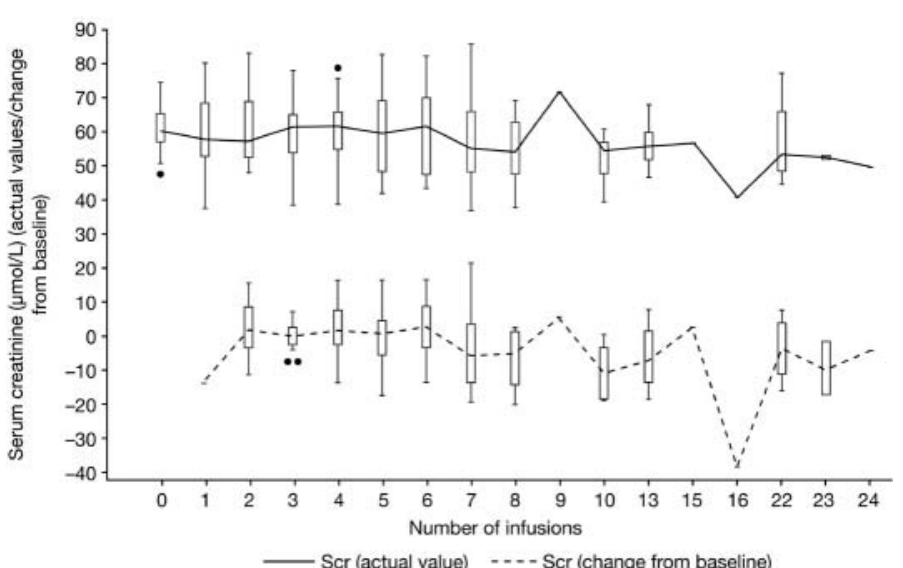

$\mathrm{Scr}=$ serum creatinine

Fig. 2. Box plot of serum creatinine ( $\mu \mathrm{mol} / \mathrm{l})$ (actual values and change from baseline) by number of infusions during core study ( 6 months) and follow-up phase (12 months): follow-up analysis population. Boxes stretch from the 25 th to the 75 th percentile. Median values are joined. Outliers are indicated by an $\bullet$.

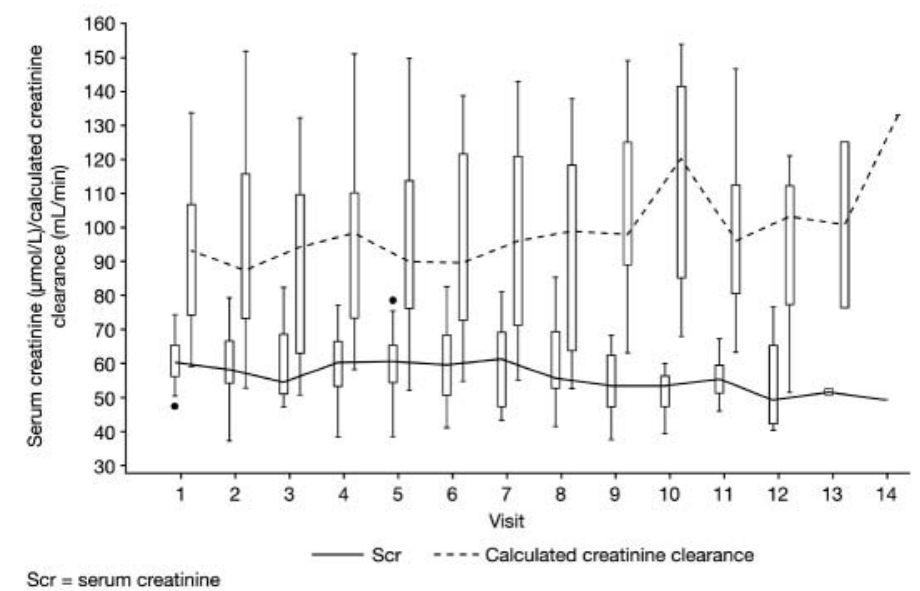

Fig. 3. Box plot of serum creatinine ( $\mu \mathrm{mol} / \mathrm{l})$ (actual values and change from baseline) and calculated creatinine clearance $(\mathrm{ml} / \mathrm{min})$ by visit during core study (6 months) and follow-up phase (12 months): follow-up analysis population. Visit 1 was the screening visit, and visit 2 was the baseline visit. Boxes stretch from the 25 th to the 75 th percentile. Median values are joined. Outliers are indicated by an $\bullet$.

patients (29\%) experienced 4 grade 3 (severe) AEs: sick sinus syndrome (also reported as a serious grade $3 \mathrm{AE}$ ), venous thrombosis, loss of appetite, and bone pain. Another patient (in addition to the patient with sick sinus syndrome) reported a serious AE: a mild worsening of her general condition. Neither serious AE was considered by the investigator to be related to study therapy, and both conditions improved following their treatment. Six AEs reported in 3 patients (21\%) were considered by the investigator to be treatment-related although none was considered severe or reported as a serious AE. No patient died during the follow-up phase. No clinically relevant changes from baseline in vital signs were reported during the follow-up study. 


\section{Discussion}

In this small population of 14 patients continuing into the follow-up phase of the earlier, open-label, prospective core study [16], there was no evidence that the 15-min infusion of $6 \mathrm{mg}$ i.v. ibandronate every 3-4 weeks was associated with a deterioration in renal function. Long-term administration (approximately 12-24 months) of i.v. ibandronate $6 \mathrm{mg}$ was generally well tolerated with an AE profile consistent with that of the core study. No new or unexpected AEs related to extended i.v. ibandronate treatment were noted. This follow-up study supports the conclusions from the core trial [16] and preclinical research [17] that $6 \mathrm{mg}$ ibandronate administered over 15 min does not cause renal tubular cell damage, interfere with renal tubular reabsorption, or affect glomerular filtration. Thus, $6 \mathrm{mg}$ i.v. ibandronate administered over 15 min offers improved convenience to patients while maintaining the good tolerability profile reported with a 60 -min infusion. Although the sample size for the follow-up study was small, the results are consistent with previously conducted clinical research [18, 19] and a growing body of other evidence suggesting that ibandronate has negligible nephrotoxicity and probably a better renal safety profile than other i.v. bisphosphonates [20]. This improved renal tolerability may be linked to differences in protein binding and renal tissue half-life [17]. Ongoing experience in the use of the regimen in real-life clinical practice will add to this accumulating data.

\section{Conclusions}

Ibandronate was well tolerated when administered as a $6 \mathrm{mg}$ i.v. infusion over 15 min every 3-4 weeks for the 12-month follow-up phase to the 6-month core study. No evidence for any treatment-related deterioration in renal function, as assessed by the change from baseline in serum creatinine and calculated creatinine clearance, was noted, and no new or unexpected AEs were seen. The 15-min ibandronate infusion offers patients a convenient therapeutic option.

\section{Acknowledgement}

F. Hoffmann-La Roche was the sponsor of this study. The authors would like to acknowledge medical writing assistance provided by Dr Louise Profit, Gardiner Caldwell Communications (Macclesfield, UK) in the preparation of this manuscript, financial support for which was provided by F. Hoffmann-La Roche.

\section{Conflicts of Interest}

Dr. Roger von Moos is an investigator in this study, has been an advisor for Roche Ltd, Novartis and Amgen, and has received speaker honoraria from Roche Ltd, Schering Plough, and Amgen. Prof. Dr. R. Steiner has received consultancy fees from Astra Zeneca and speaker honoraria from Organon. Dr. R. Angst was an employee of Bayer Healthcare for 1.5 years until April 2009. Dr. K. Schmieding is an employee of F. Hoffmann-La Roche and holds stocks with Roche. Dr B. Thürlimann holds stocks with Roche and has received honoraria from Roche for advisory board and educational activities. Dr. C. B. Caspar and Dr. R. Inauen have no conflicts of interest.

\section{References}

$\checkmark 1$ Coleman RE: Bisphosphonates: clinical experience. Oncologist 2004;9(suppl 4):14-27.

2 Pavlakis N, Schmidt R, Stockler M: Bisphosphonates for breast cancer. Cochrane Database Syst Rev 2005;3:CD003474.

3 Hillner BE, Ingle JN, Chlebowski RT, Gralow J, Yee GC, Janjan NA, Cauley JA, Blumenstein BA, Albain KS, Lipton A, Brown S: American Society of Clinical Oncology 2003 update on the role of bisphosphonates and bone health issues in women with breast cancer. J Clin Oncol 2003;21:4042-4057.

4 Bondronat: Summary of Product Characteristics, March 2007. emc.medicines.org.uk/medicine/8600/ SPC/Bondronat/\#INDICATIONS. Accessed 27 October 2009.

${ }_{5}$ Body JJ, Diel IJ, Lichinitser MR, Kreuser ED, Dornoff W, Gorbunova VA, Budde M, Bergström B, MF 4265 Study Group: Intravenous ibandronate reduces the incidence of skeletal complications in patients with breast cancer and bone metastases. Ann Oncol 2003;14:1399-1405.

6 Body J, Kanis J, Diel I, Bergström B: Risk reductions in metastatic breast cancer: multivariate poison regression analyses of oral and i.v. ibandronate. Proc Am Soc Clin Oncol 2003;22:46.

7 Diel IJ, Body JJ, Lichinitser MR, Kreuser ED, Dornoff W, Gorbunova VA, Budde M, Bergström B, MF 4265 Study Group: Improved quality of life after long-term treatment with the bisphosphonate ibandronate in patients with metastatic bone disease due to breast cancer. Eur J Cancer 2004:40:1704-1712.
8 Zazgornik J, Grafinger P, Biesenbach G, Hubmann R, Fridrik M: Acute renal failure and alendronate. Nephrol Dial Transplant 1997;12:2797-2798.

-9 Janssen van Doorn K, Neyns B, Van der Niepen P, Verbeelen D: Pamidronate-related nephrotoxicity (tubulointerstitial nephritis) in a patient with osteolytic bone metastases. Nephron 2001;89:467-468.

10 Rosen LS, Gordon D, Kaminski M, Howell, A, Belch A, Mackey J, Apffelsteadt J, Hussein M, Coleman RE, Reitsman DJ, Seaman JJ, Chen BL, Ambros Y: Zoledronic acid versus pamidronate in the treatment of skeletal metastases in patients with breast cancer or osteolytic lesions of multiple myeloma: a phase II, double-blind, comparative trial. Cancer J 2001;7:377-387.

11 Body JJ: Dosing regimens and main adverse events of bisphosphonates. Semin Oncol 2001;28(4 suppl 11):49-53.

12 Markowitz GS, Fine PL, Stack JI, Kunis CL, Radhakrishnan J, Palecki W, Park J, Nasr SH, Hoh S, Siegel DS, D'Agatti VD: Toxic acute tubular necrosis following treatment with zoledronate (Zometa). Kidney Int 2003;64:281-289.

13 Chang JT, Green L, Beitz J: Renal failure with the use of zoledronic acid. N Engl J Med 2003;349: 1676-1679.

14 Stopeck A, Body JJ, Fujiwara Y, Lipton A, Steger GG, Viniegra M, Fan M, Braun A, Dansey R, Jun S: Denosumab versus zoledronic acid for the treatment of breast cancer patients with bone metastases: results of a randomized phase 3 study. Eur J Cancer Suppl 2009;7:2.
15 Henry D, von Moos R, Vadhan-Raj S, Hungria V, Spencer A, Hirsh V, Wang J, Jun S, Yeh H, Dansey R: A double-blind, randomized study of denosumab versus zoledronic acid for the treatment of bone metastases in patients with advanced cancer (excluding breast and prostate cancer) or multiple myeloma. Eur J Cancer Suppl 2009;7:11.

16 Von Moos R, Caspar CB, Thürlimann B, Angst R, Inauen R, Greil R, Bergstrom B, Schmiedling K, Pecherstorfer M: Renal safety profiles of ibandronate $6 \mathrm{mg}$ infused over 15 and $60 \mathrm{~min}$ : a randomized, open-label study. Ann Oncol 2008;19:12661270 .

17 Body JJ, Pfister T, Bauss F: Preclinical perspectives on bisphosphonate renal safety. Oncologist 2005; 10(suppl 1):3-7.

18 Neugebauer G, Köhler W, Akinkunmi L, Pinner J, Kletzl H, Banken L: Influence of peak ibandronate concentrations after $6 \mathrm{mg}$ IV administration with shortened infusion time (15 and 30 minutes) on renal safety in man. J Clin Oncol 2001;20:122a.

19 Body JJ, Lichinister M, Andreeva N, Budde M, Bergtröm B: Safety of an intravenous (i.v.) dose of ibandronate followed by daily oral dosing in metastatic bone disease: results of an open-label study. J Clin Oncol 2004;22(suppl 14):60.

20 Perazella MA, Markowitz, GS: Bisphosphonate toxicity. Kidney Int 2008;74:1385-1393.

von Moos/Caspar/Steiner/Angst/Inauen/ Schmieding/Thürlimann 